\title{
A Methodology to Empirically Assess National and Farm-Specific Damages from Contamination of Grain Supply by a Genetically Engineered Strain
}

\author{
Oral Capps, Jr. ${ }^{1 * *}$ and Ronald A. Babula ${ }^{2, * *}$ \\ ${ }^{1}$ Department of Agricultural Economics, Texas A\&M University, College Station, Texas, USA and ${ }^{2}$ Department of Economics \\ and Finance, Keimyung University, Daegu, South Korea \\ ${ }^{*}$ Corresponding author. Email: ocapps@tamu.edu \\ ${ }^{*}$ Currently retired in Washington, D.C., USA
}

\begin{abstract}
On May 29, 2013, the U.S. government announced that contamination of non-genetically engineered wheat supplies occurred. We provide a methodology to empirically assess the impacts of this contamination event on national prices and on farm-specific prices and receipts for spring red hard wheat. Results suggest that U.S. spring red hard wheat farmers in the aggregate had lost receipts ranging from $\$ 32.77$ million to $\$ 131.06$ million and incurred a drop of $3.83 \%$ in wheat price equivalent to $\$ 0.27$ per bushel. At the farm level, a hypothetical farmer received $\$ 0.31$ less per bushel culminating in $\$ 4,807$ in lost receipts.
\end{abstract}

Keywords: Assessment of national and farmer-specific damages; genetically engineered wheat; May 2013 wheat contamination; use of vector error correction model

JEL Classifications: C39; C51; Q11

\section{Introduction}

Generally, much of the foreign demand for U.S. crops is constituted by notable importing nations who are averse to accepting genetically modified (or GM) crops and food products made with such crops because of perceived health risks to the environment and their populations (Carter and Smith, 2007, p. 522; Li et al., 2010, p. 31). Quite simply, when the United States has, on a number of occasions noted subsequently, announced that crop supplies have been contaminated with GM crop varieties or strains that have not been approved for human consumption, world demand for U.S. crops has fallen significantly and led to declines in U.S. farm prices, farm receipts, and farm income. There have been a number of studies that have estimated the U.S. national or "sectorlevel" crop price effects of such contamination events (see, e.g., Carter and Smith, 2007; Li et al., 2010). Yet to date, we have been unable to locate studies that provide a methodology to take such national or sector-level effects and translate them into adverse decreases in farm-specific prices received, cash receipts, and income for use by plaintiffs in litigation that usually follows contamination events.

In April 2013, an Oregon wheat farmer discovered a strange strand of wheat growing where no wheat previously had been planted. The U.S. Department of Agriculture (see U.S. Department of Agriculture, Animal and Plant Health Inspection Service [USDA-APHIS], 2018) ultimately identified this strand as a genetically engineered (GE) strain developed by Monsanto and called the Roundup Ready strain (hereafter, the GE/RR wheat strain). In 1997, Monsanto began 
development of the GE/RR strain, and over the 1998-2005 period tested this strain on 100 field sites in 16 U.S. states, before ultimately pulling its application. In the end, the GE/RR strain of wheat was not approved by the USDA (Boone, 2013; Jalonick, 2013; Thukral and Maeda, 2013). This unapproved GE/RR wheat strain ultimately contaminated non-GE wheat supplies not only in Oregon but nationwide. In the immediate 2-month aftermath of the discovery of the GE/RR wheat strain on the noted Oregon farm, a number of news sources provided reports of the contamination's potential consequences. Klein (2013) reported alleged consequences that included South Korea and Japan (two important importers of U.S. wheat) cancelling some contracts to purchase U.S. wheat, the European Union having implored its 27 member nations to increase inspections of imported U.S. wheat, and certain wheat futures contract prices having fallen on the Chicago Board of Trade.

Given the nonapproved status by the USDA of the GE/RR wheat strain, and given its contamination of various U.S. state supplies of non-GE wheat, court cases were filed in various U.S. states against Monsanto. Such cases basically alleged that farmers would incur lost sales and depressed wheat market prices because of the effects of such contamination of non-GE U.S. wheat supplies by the GE/RR strain. The filings by farmers further contended that Monsanto should have known that it was virtually impossible to prevent the GE/RR strain's contamination of other non-GE wheat supplies given that the U.S. wheat system comingles wheat deliveries from thousands of U.S. farms for sales and shipping (Bjerga, 2013; Boone, 2013; Jalonick, 2013; Thukral and Maeda, 2013). As explained by Bjerga (2013), the actual or perceived existence of such a GE wheat strain as RR would likely dampen U.S. wheat export demand and lower U.S. wheat prices insofar as a multitude of U.S. wheat-importing clients are averse to GE supplies of grain and other agricultural products.

In May 2013, when the GE/RR wheat strain contamination incident occurred, projections suggested that about 140 to 150 million tons of wheat were globally traded, and about a third of this trade flow was U.S. sourced, rendering a sizable source of payments to U.S. wheat farmers. Japan alone was importing about 40 million tons of wheat annually and sourcing about a third from the United States. "GE-adverse" Asian wheat importers-Japan, South Korea, and the Philippines in particular-were reported to be very concerned over the May 2013 GE event and, consequently, were reconsidering their wheat import tenders and deals until the U.S. government assured them that U.S. wheat export supplies were not contaminated with the GE product. The U.S. Department of Agriculture (U.S. Department of Agriculture, Economic Research Service [USDA-ERS], 2013) data available at the time of litigation suggested that U.S exports of nondurum wheat declined 26.5\% during the first few months after the May 2013 announcement.

\section{Purpose}

In his oft-cited article concerning the use of econometric work in the courtroom, Rubinfeld (1985, p. 1048) noted that "the use of statistical methods for resolving disputes has found increasing acceptance within the adversary system" and has "opened the door to law-related econometric studies, particularly in connection with the use of multiple regression models." The 2013 U.S. wheat contamination incident and similar episodes with other U.S. agricultural products reviewed in Section 3 generally have the potential to substantially decrease U.S. farmer revenues through reduction in U.S. export sales of the relevant commodities and through lower farm prices received. The literature has provided econometric methodologies to estimate adverse GE event-induced price effects that could be tied to declines in farm revenues and income for the nationwide crop sector subject to the contamination. Yet to date, some 34 years after Rubinfeld's (1985) previously mentioned comments, the literature does not provide a methodology to assess how such contamination events negatively influence prices and receipts at the farm-specific plaintiff level (Carter and Smith, 2007; Li et al., 2010). 
Immediately after the $2013 \mathrm{GE} / \mathrm{RR}$ event, court cases were filed by farm-specific plaintiffs that produce the non-durum classes of wheat. The lack of a methodology to help these wheat farmer plaintiffs highlighted a long-standing and continuing need by the economics profession for an appropriate methodology. Our goal here is for an applied methodological contribution lacking in the literature, in particular extending econometric sector-wide studies focused on the national crop market effects to estimation of effects on farm-specific plaintiffs so as to enhance our profession's participation/usefulness in related litigation. Guided by prior relevant literature that uses time-series cointegration modeling techniques to discern contamination-induced national price effects for other crops, we estimate U.S. wheat sector effects induced by the 2013 wheat contamination event and then use these sector-level effects to estimate farm-specific plaintiff effects of the contamination on farm-level prices, sales receipts, and farm income for use by plaintiffs in litigation that followed the event.

\section{Prior related work}

Two studies that applied time-series econometric methods to estimate sector-wide effects of GM variety contaminations of U.S. corn and rice supplies were deemed relevant to our study on wheat. Both studies applied time-series econometric models at the crop sector-level to capture long-run reduced-form cointegrated relationships among prices for a U.S. crop sector supply contaminated with a GM variety, as well as for a substitute crop.

Carter and Smith (2007) used cointegration and other time-series methods to examine the 2000 contamination of U.S. food corn supplies by the StarLink corn variety, a GM strain not approved by the U.S. government for human consumption. They proposed a forecasting model based on cointegration between the price of U.S. food corn and the price of sorghum (a corn substitute in certain usage categories) not directly affected by the event. They discerned a StarLink eventinduced departure from a stable cointegrating relationship among U.S. corn and sorghum prices assessed through tests of structural breaks to identify the relevant StarLink event dates. They split the entire sample into pre- and postcontamination subsamples. They then estimated the magnitude of the StarLink event effects through a comparative analysis of the difference in two sets of postevent prices: observed U.S. corn prices and what the "benchmark" U.S. food corn prices would have been had the event not occurred. Among their results, Carter and Smith (2007, pp. 531-33) concluded that the StarLink corn variety's contamination of U.S. food corn supplies elicited a $6.8 \%$ decline in U.S. corn prices that persisted for at least a year.

Li et al. (2010) used time-series cointegration modeling methods to assess impacts on U.S. rice market prices from the 2006 contamination (officially announced on August 18) of U.S. rice supplies by the Liberty Link Rice 601 (LL601) variety that was not approved by the U.S. government for human consumption. They used methods of Engle and Granger (1987) and Engle and Yoo (1987) and tested for cointegration between weekly U.S. rice futures prices affected by the LL601 contamination and prices of the closest discernable substitute in global markets-namely, Thai rice (Li et al., 2010, p. 32). Without having formally tested for the contamination-induced structural breaks, they assumed that such contamination-induced structural breaks had occurred and then split their full sample into pre- and postcontamination subsamples. They then tested for, found, and estimated a long-run equilibrium relationship between the weekly U.S. and Thai rice prices, following the methods of Engle and Granger (1987), and used the residuals of this relationship to estimate a two-price error correction model (ECM). The ECM was then used to forecast prices over a post-LL601 period and to determine what "benchmark" prices would have been without the LL601 contamination event (Li et al., 2010, pp. 33-34). Among their results, Li et al. (2010, pp. 34-36) concluded that LL601 contamination-induced U.S. rice price declines were dramatic but short lived, with U.S. price having declined up to about $17 \%$ within 2 weeks of the contamination and having fully recovered within a month of the announcement. 


\section{Stages of the assessment methodology for the non-GE wheat contamination incident}

A reliable analytical procedure for empirically assessing the impacts on relevant U.S. product markets and on firm-specific plaintiffs affected by such an incident as the May 2013 GE event would be composed of several steps.

- First, one discerns the products allegedly affected by the monitored event, here the wheat classes affected by the May 29, 2013, incident. The four (non-durum) classes of U.S. wheat potentially affected by the event were winter white soft wheat, winter red hard wheat, winter red soft wheat, and spring red hard wheat. This phase constitutes tier 1 of the proposed methodology and needs no further discussion. A plot of the monthly four U.S. wheat class prices is provided in Figure 1-namely, winter red soft wheat, winter red hard wheat, spring red hard wheat, and winter white wheat. Winter red soft wheat primarily is grown in parts of Texas, Louisiana, Mississippi, Arkansas, Tennessee, Missouri, Illinois, Indiana, Ohio, Georgia, South Carolina, North Carolina, Virginia, Maryland, Delaware, and Pennsylvania. Winter red hard wheat largely is produced in parts of Texas, Oklahoma, Kansas, Nebraska, New Mexico, Colorado, Wyoming, South Dakota, Montana, and California. Spring red hard wheat is produced in Washington, Idaho, Montana, North Dakota, South Dakota, and Colorado. Finally, for the most part, winter white wheat is grown in Idaho, Washington, and Oregon. For considerations of space, and given our aforementioned analytical purpose, we focus throughout only on one chosen class of affected U.S. wheat-namely, spring red hard wheat - while noting that our methodology developed here may be replicated for discerning the impacts on the receipts and prices of the other three U.S. wheat classes. Note too that spring red hard wheat and winter wheat are indigenous to the area of the unapproved GE/RR wheat strain. Our efforts applied to a system of four prices were guided by the bivariate cointegration modeling procedures of Carter and Smith (2007) and Li et al. (2010) that exploited the long-run cointegration relationship among the contaminated crop price and the price of the nearest discernible substitutes.

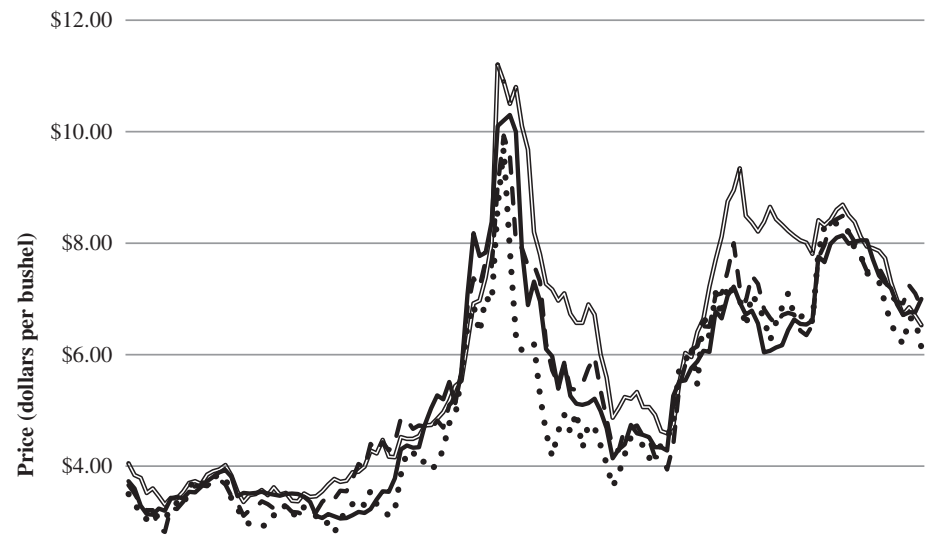

Figure 1. Monthly national wheat prices received by farmers, January 2003 to December 2013.

Source: U.S. Department of Agriculture, National Agricultural Statistics Service.
$\$ 2.00$

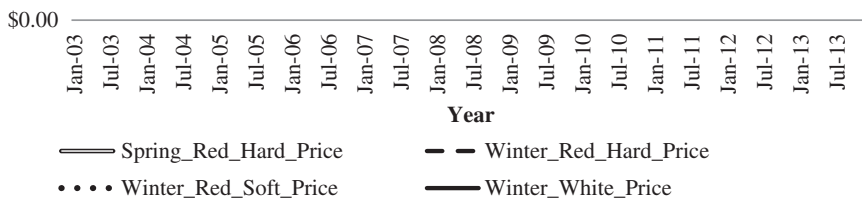


- Second, one must empirically discern the incident's impacts on national U.S. product prices, with our focus here illustratively placed on the price of U.S. spring red hard wheat (hereafter, PSPRRDHD). The USDA's National Agricultural Statistics Service (NASS) publishes monthly prices for the previously mentioned four non-durum wheat classes (see USDA-NASS, 2018). For reasons discussed in Section 5, this stage includes the specification, estimation, and application of a state-of-the-art cointegrated vector autoregression (VAR) econometric model (sometimes denoted as a vector error correction [VEC] model) of all four U.S. wheat class prices, including PSPRRDHD on which attention is centered here. Given Carter and Smith's (2007) useful review of an array of potential modeling strategies, we chose, for reasons cited in Section 5, from this array, the strategy that combines a reduced-form cointegrated VAR model of substitute prices with a "shifter variable" defined for the specific contamination event, whereby the "shifter" is useful in discerning the event-induced price impacts.

- Third, one calculates national damages to U.S. producers of the relevant product market, here all U.S. farmers of spring red hard wheat. We develop a methodology to estimate declines in PSPRRDHD and declines in U.S. farm receipts from sales of spring hard red wheat that are considered damages attributed to the May 2013 GE event.

- Fourth, we demonstrate how one would use econometrically estimated national price declines attributed to the event to the firm-specific records of plaintiffs involved in the class action suit that arise from the monitored action-hypothetically for a single plaintiff farmer of spring red hard wheat in response to the May 2013 GE event.

Anonymous reviewers insightfully suggested that we apply this methodology to all five U.S. wheat classes (including durum) rather than just to our chosen single class, spring red hard wheat. We opted to limit the study to this single illustrative wheat class largely based on the fact that spring red hard wheat is native to the 16-state area of the GE/RR wheat contamination. We also appeal to Sims's (1989) principle that a meaningful modeling effort should be, in part, tailored to the analytical purpose at hand. Insofar as farm-specific litigants' own financial records would have been ideal here, such records are not within the public domain. So in order to achieve our secondtier goal of translating national impacts to the farm level, we use records for a hypothetical spring red hard wheat farmer.

The relevant studies in the extant literature discussed previously had the goal or analytical purpose of econometrically estimating the adverse national or U.S. crop sector-level price impacts of a contamination event: Carter and Smith (2007) for corn and Li et al. (2010) for rice. Our study's analytical purpose is two-tiered and is expanded to not only econometrically estimate the 2013 GE/RR wheat contamination effects on national U.S. wheat class prices (tier 1) but also provide a methodology, lacking at the onset of the $2013 \mathrm{GE} / \mathrm{RR}$ contamination event, that is useful in litigation and that translates the national effects to plaintiff/farm-specific declines in prices received, revenue lost, and implied declines in farm income (tier 2). Supported by Sims's (1989) well-known modeling criteria, and given this extended analytical purpose at hand, we chose to limit the study to one illustrative wheat class in order to avoid excessive page length and to avoid what we believe would be an overly "replicative" array of four similar non-durum wheat class calculations and analyses. As noted previously, we believe our analysis illustratively provided for spring red hard wheat can be seamlessly adopted by farmers of other wheat classes and to other nonwheat crop markets.

\section{Using cointegration "reduced-form" models for contamination events}

Carter and Smith (2007, pp. 524-26) discussed a number of alternative modeling methodological options in order to estimate adverse price effects for a U.S. crop with an emphasis on corn. Their idea is to compare, for a postevent period, observed crop prices with benchmark crop price 
forecasts reflecting what such postevent prices would have been had the contamination event not occurred. The "would be" postevent benchmark prices would be generated by a structural demand and supply model of the contaminated U.S. crop sector or market. Another of Carter and Smith's proposed options would include a "shifter" variable in the estimated U.S. structural crop sector model. The shifter's coefficient estimate could then be used to discern significant event-induced price effects (Carter and Smith, 2007, p. 526).

Yet for U.S. crop sector markets generally, Carter and Smith (2007) noted the well-known specification and enormous data procurement problems of estimating such structural models. With problems that were similarly noted for modeling the national U.S. corn market, our U.S. wheat market is composed of four wheat class submarkets; there are a wide array of client demands for each submarket (domestic food, domestic feed, foreign food, and foreign feed demands); and each demander's preference function in each submarket is unique (see Carter and Smith 2007, pp. 524-27). Carter and Smith then recommended using reduced-form cointegration modeling methods that exploit the high-quality U.S. crop price data published by NASS. These reduced-form models exploit the long-run equilibrium or cointegrating relationships of the price of the contaminated crop and prices of substitutes that were not directly contaminated. Such reduced-form models could avoid the noted specification and data collection problems of estimating the contaminated sector's structural demand-supply model (Carter and Smith 2007). As an alternative to their use of a reduced-form cointegrated model of substitute prices combined with structural break analysis, they suggested taking the cointegrated VAR model and combining it with a "shifter" variable that may be used to discern event-specific national crop price effects (Carter and Smith 2007, p. 525).

For reasons detailed in Section 5.3, we follow this latter Carter and Smith (2007) strategy and combine the reduced-form cointegrated VAR model (or VEC model) of four prices of U.S. wheat classes (well-known substitutes in consumption and production) with a "shifter" variable. Our shifter variable follows Juselius's (2006)) widely applied "permanent shift dummy or binary" variable of use in empirically discerning impacts of such event-specific events as the 2013 U.S. wheat supply contamination.

We conducted Juselius's (2006, chap. 9) "known-beta" test for time invariance of estimated parameters, with time variance of such parameters considered as a "structural break." Because our test results (provided in Section 5.3) suggested that the contamination did not result in time variance of the estimated parameters in our model, we chose not to follow Carter and Smith's (2007) strategy under conditions of a structural break and where the full sample is split into pre- and postcontamination subsamples. We rather opted for Carter and Smith's (2007) alternative of combining the cointegrated VAR model with a shifter variable - that is, with Juselius's (2006) permanent shift dummy variable in the cointegration space. Use of such a dummy variable is valid over the full sample when the event for which this variable is defined (here the 2013 U.S. wheat contamination) does not induce time variance of estimated parameters or a structural break.

The prime focus of this analysis is to combine widely applied econometric tools with basic accounting procedures to empirically assess contamination-induced adverse negative impacts on U.S. wheat prices and then illustratively apply the methodology to calculate plaintiff-specific effects for one of the four non-durum wheat classes, spring red hard wheat. As a result, we do not dwell on the widely accepted and applied econometric tools themselves but rather demonstrate how such tools are applied. Consequently, we provide only summaries of the econometric output when required of the methodology developed here.

\subsection{Background on cointegration}

Achieving our analytical purpose would first require estimated price impacts of the event using a highly periodic (here monthly) time-series econometric model of the four non-durum 
U.S. wheat class prices (see Figure 1), because they are substitutes in production and consumption. For reasons discussed in the following three paragraphs and in Sections 5.2 and 5.3, we chose the modeling approach known as the cointegrated VAR or VEC model approach to model the four U.S. wheat class prices in order to capture the long-run forces (cointegrating relationships or cointegrating vectors $[\mathrm{CVs}]$ ) that drive the individually nonstationary prices to move in a general tandem pattern.

It is well known that economic variables often fail to achieve conditions of weak stationarity required of valid inference. ${ }^{1}$ Prior to the work by Engle and Granger (1987) on cointegration, econometric analysts often first-differenced nonstationary variables that were used in modeled estimations. $^{2}$

In cases such as ours, with four individually nonstationary prices, Johansen and Juselius (1990), following Engle and Granger (1987), demonstrated that individually nonstationary series may form a group of interrelated or cointegrated variables that behave as a group in a stationary manner over time. As a result, the traditional remedy of differencing such individually nonstationary variables would jettison important long-run components (i.e., cointegrating relationships or CVs) that are crucial in explaining long-run behavior. So although differencing such cointegrated variables would achieve stationarity of the modeled time series, estimates from such differenced data would likely incur misspecification bias from omitted relevant information, the CVs. It is wellknown that the cointegrated VAR approach permits the retention of levels-based CVs in a reduced-rank "error correction" space, so as to achieve stationarity requirements (and noncompromised inference) while avoiding difference-induced misspecification bias (Engle and Granger, 1987; Johansen and Juselius, 1990).

We first achieve a statistically adequate underlying (unrestricted) model. Second, we test for and impose cointegration restrictions on the four U.S. wheat class prices. We then focus on and interpret the cointegration parameter estimates necessary to formulate a methodology that estimates GE event-induced declines in prices and receipts at the national and plaintiff-specific levels for an illustrative class of U.S. wheat-namely, spring red hard wheat.

\subsection{Statistically adequate underlying model and Haavelmo's ceteris paribus conditions}

It is well-known that an unrestricted VAR model of the noted wheat prices in (here logged) levels posits each U.S. wheat class price as a function of $k$ (here $k=6$ ) lags of itself and of $k=6$ lags of the three remaining prices. ${ }^{3}$ Johansen and Juselius (1990) demonstrated that such a levels VAR model may be rewritten into an algebraically equivalent unrestricted VEC model:

$$
\begin{aligned}
\Delta x(t)= & \Gamma(1) \times \Delta x(t-1)+\ldots+\Gamma(k-1) \times \Delta x(t-k+1)+\Pi \times x(t-1)+\Phi D(t) \\
& +\varepsilon(t) .
\end{aligned}
$$

\footnotetext{
${ }^{1}$ Throughout, nonstationary data refer to those that are integrated of order $1,[\mathrm{I}(1)]$, whereas stationary data refer to those that are integrated of order zero [I(0)]. Throughout, "levels variables" are modeled in natural logarithms.

${ }^{2}$ As a preliminary analysis, we performed augmented Dickey Fuller (ADF) tests on the four logged prices (see Dickey and Fuller, 1981; Hamilton, 1994). Because the ADF $t \mu$ values were all negative and 2.12 or less in absolute value, and well below the $5 \%$ absolute value of 2.89 , this suggested that the evidence was insufficient to reject the null hypothesis of nonstationarity in all four cases. Additionally, we employed the systems-based and rank-dependent multivariate unit root tests that emerged from the cointegrated VAR model ultimately estimated in Section 5.2 and recommended by Johansen and Juselius (1990), Juselius (2006), Juselius and Toro (2005), and Juselius and Franchi (2007). These tests generated the following test statistic $P$ values that were all below $5 \%$ and suggested that evidence was sufficient to reject of the null hypothesis of stationarity: price of spring red hard wheat (PSPRRDHD; $P=0.007$ ), price of winter red hard wheat (PWINRDHD; $P=0.01$ ), price of winter red soft wheat (PWINRDSF; $P=0.01$ ), and price of winter white soft wheat (PWINWHSF; $P=0.04$ ).

${ }^{3} \mathrm{~A} k=6$ lag structure was used by employing a likelihood ratio test lag search procedure as recommended by Juselius (2006).
} 
Supported by diagnostic evidence reported in the remainder of this section, we specified the model with linear trends in the variables and the cointegrated relationships. The number of endogenous variables, denoted as $p$, is 4 . The $\epsilon(t)$ terms are white noise residuals, the delta is the difference operator, and $x(t)$ and $x(t-1)$ are $p$ by 1 vectors of the endogenous variables in current and lagged levels. The $\Gamma(1), \ldots, \Gamma(k-1)$ terms are $p$ by $p$ matrices of short-run regression coefficients, and $\Pi$ is a $p$ by $p$ long-run error correction term to account for endogenous levels. The other terms are collectively referred to as the model's short-run/deterministic or "short-run" component. The $\Phi D(t)$ corresponds to a set of deterministic variables, including an array of binary variables that will be added to address stationarity and specification issues discussed in the remainder of this section. From Engle and Granger (1987) and Johansen and Juselius (1990), the error correction term is decomposed as follows:

$$
\Pi=\alpha \times \beta^{\prime} .
$$

The $\alpha$ is a $p$ by $r$ matrix of adjustment coefficients or "alphas" where $r$ is the number of cointegrating relationships or the rank of $\Pi$ discussed in Section 5.3. The $\beta$ is a $p$ by $r$ vector of cointegrating parameters or "betas." $\Pi$ captures level-based long-run information: stationary linear combinations of the nonstationary levels data under cointegration, permanent shift binaries to capture long-run impacts of policies and/or market events, and a linear trend.

We followed the recommended methods of Juselius (2006) to include several sorts of binary variables to address an array of stationarity and specification issues. A set of 11 binary variables was included to account for seasonality of U.S. wheat crop prices. In addition, we included the following "permanent shift" binary variables in levels within $\Pi$ and in differenced form within the short-run component of equation (1):

- RECESS in order to account for the wheat market effects of the U.S. economic recession during December 2007 through June 2009.

- FB2008 in order to account for the U.S. wheat market impacts of the 2008 U.S. farm bill.

- GEEVENT in order to capture the immediate influences on the four endogenous wheat class prices of such an event as the GE event that occurred in May 2013. Valued at unity for June 2013 and July 2013, and at zero otherwise, this binary variable accounts for the event-induced market effects such as cancellation of foreign import orders for U.S. wheat, coincidental wheat futures market price declines, among other things, reported during the immediate months following the event's May 2013 occurrence by Bjerga (2013), Boone (2013), Klein (2013), Jalonick (2013), and Thukral and Maeda (2013). Although the U.S. wheat contamination was discovered in April, we opted to not to include April in GEEVENT's definition because we located no evidence of a news leak before the USDA's official announcement on May 29, 2013. Because the USDA's announcement of the GEEVENT event was on May 29, 2013, with most of the month (all but two full days) having already passed, and with little or no possible GE/RR event influence on the USDA's estimates of the May 2013 wheat class prices, we chose to begin GEEVENT with June 2013 (see USDA-APHIS, 2018) and exclude May 2013 that some may have preferred to have been included. This GEEVENT binary is of particular use in our study because in addition to being consistent with the national contaminationinduced effect estimates in tier 1, the binary's definition is also consistent with tier-2 effect estimates because farmer plaintiffs who filed in the actual court case did so for marketings of spring red hard wheat sold over the June-July 2013 period.

Moreover, following Juselius (2006), other "outlier" binary variables were included in the shortrun component of equation (1). These binary variables were designed to account for "extraordinary" and exogenous wheat market influences attributed to short-run events not of direct 
Table 1. Misspecification tests for the unrestricted model before and after specification enhancement efforts

\begin{tabular}{|c|c|c|c|}
\hline Test & Null Hypothesis and/or Test Explanation & $\begin{array}{c}\text { Prior Specification } \\
\text { Efforts }\end{array}$ & $\begin{array}{c}\text { After Specification } \\
\text { Efforts }\end{array}$ \\
\hline Trace correlation & Goodness of fit; large proportion desirable & 0.345 & 0.626 \\
\hline $\begin{array}{l}\text { LM test serial correlation } \\
\text { (at lag } 1 \text { ) }\end{array}$ & $\begin{array}{l}\mathrm{H}_{0} \text { : No serial correlation of the residuals. } \\
\text { Reject the null hypothesis when the test } \\
\text { statistic }>\chi^{2} \text { critical value of } 32.0 \text {. }\end{array}$ & 11.63 & 17.11 \\
\hline ARCH test (at lag 1 ) & $\begin{array}{l}\mathrm{H}_{0}: \text { No heteroscedasticity of the residuals. } \\
\text { Reject the null hypothesis when the test } \\
\text { statistic }>\chi^{2} \text { critical value of } 135.80 \text {. }\end{array}$ & 105.28 & 104.76 \\
\hline $\begin{array}{l}\text { Doornik-Hansen test, } \\
\text { system-wide }\end{array}$ & $\begin{array}{l}\mathrm{H}_{0} \text { : The residuals of the system behave } \\
\text { normally. Reject the null hypothesis when } \\
\text { the test statistic }>\chi^{2} \text { critical value of } 20.09 \text {. }\end{array}$ & 62.23 & 9.07 \\
\hline $\begin{array}{l}\text { Univariate Doornik- } \\
\text { Hansen tests }\end{array}$ & $\begin{array}{l}\mathrm{H}_{0} \text { : The residuals of each equation behave } \\
\text { normally. Reject the null hypothesis when } \\
\mathrm{D}-\mathrm{H} \text { test statistics }>9.2 \text {. }\end{array}$ & & \\
\hline$\triangle$ PSPRRDHD & & 34.380 & 0.180 \\
\hline$\triangle P W I N R D H D$ & & 13.110 & 0.880 \\
\hline$\triangle P W I N R D S F$ & & 13.590 & 0.024 \\
\hline$\triangle \mathrm{PWINWHSF}$ & & 16.650 & 3.630 \\
\hline Skewness (kurtosis) values & $\begin{array}{l}\text { Skewness: small values acceptable. } \\
\text { Kurtosis: acceptable range }<5.0\end{array}$ & & \\
\hline$\triangle P S P R R D H D$ & & $1.20(8.54)$ & $0.07(2.92)$ \\
\hline$\triangle \mathrm{PWINRDHD}$ & & $0.75(3.59)$ & $-0.13(3.13)$ \\
\hline$\triangle P W I N R D S F$ & & $0.81(3.95)$ & $0.026(2.78)$ \\
\hline$\triangle \mathrm{PWINWHSF}$ & & $0.98(5.12)$ & $-0.17(3.60)$ \\
\hline
\end{tabular}

Notes: Kurtosis values are in parentheses. ARCH, autoregressive conditional heteroscedasticity; D-H, Doornik-Hansen; LM, Lagrangian multiplier; PSPRRDHD, price of spring red hard wheat; PWINRDHD, price of winter red hard wheat; PWINRDSF, price of winter red soft wheat; PWINWHSF, price of winter white soft wheat.

relevance to the model being estimated. ${ }^{4}$ Juselius (2006) recommends this binary variable-based procedure, which focuses on achievement of Haavelmo's (1944) well-known conditions that use "statistical devices" that clear the data of extraneous exogenous effects not of direct theoretical

${ }^{4}$ Following Juselius (2006), an event that occurred over short-run subsamples was considered potentially extraordinary if its standardized residual exceeded 3.0 in absolute value. We followed recent procedures applied by Clements, Tidwell, and Jin (2017) and designed this rule on the effective sample size of $T$ observations (126 observations in our analysis) using the Bonferoni criterion programed in Estima (RATS package, Version 8.2): INVNORMAL $(1-1.025)^{T}$. INVNORMAL is a function for the normal distribution that returns the variable for the cumulative density function as a standard normal distribution and suggested that the absolute value of the Bonferoni value was 3.54. Following Clements, Tidwell, and Jin (2017), having seen that there were some short-term events with potentially extraordinary effects with absolute standardized residuals that fell between 3.0 and 3.54, we chose a more conservative absolute value criterion of 3.0 rather than 3.54. Four short-run binary variables were specified and are herein identified by the defining event dates for which they take unity values (zero otherwise), and they were then included in differenced form in the short-run component of equation (1). The first three were similar to and similarly rationalized for model inclusion in Babula's (2011) cointegrated VAR modeling study of monthly U.S. wheatbased prices. The first two binaries were included to collectively account for the anticipatory effects of the 2008 U.S. Farm Bill's implementation and for the 2007-2008 global spike in commodity demands and prices: one takes a 1.0 value for the February-June 2008 period and the other for the September 2007-April 2008 period. The third was defined for July 2010 through the sample's end to account for the effects of accelerating U.S. economic activity and the marked fall in global commodity prices (Babula, 2011). A fourth and final binary variable was defined for the July 2012 period and attempts to capture some of the 2012 anticipatory effects as the U.S. Congress moved to formulate a 1-year extension of the 2008 Farm Bill, legislation that was implemented on January 1, 2013. 
relevance to the modeled market relationships. These binary variables are included only in the model's short-run component and not in the long-run cointegration space. Consequently, we follow Clements, Tidwell, and Jin (2017) and, aside from indicating from which exogenous events the outlier binary variables may arise, we do not analyze or discuss these binary variables at length.

Following Juselius (2006), when a binary variable was identified, the variable or variable group was included in the appropriate parts of equation (1), equation (1) was reestimated, and the binary variable was retained if a battery of diagnostics suggested enhanced specification. We do not focus on the econometric output that is not directly related to our analytical goal of developing a methodology to assess damages of such an event as the May 2013 GE/RR event. However, as exhibited in Table 1, we demonstrate that we achieved a statistically adequate underlying model.

Table 1 permits a comparative analysis of evidence from a battery of diagnostics generated by the first and last estimations of an unrestricted VEC (equation 1) in our quest for enhanced specification. Prior to specification enhancement efforts, evidence suggested issues with nonnormal residual behavior, particularly at the univariate level for all four endogenous prices. After a series of reestimations with statistically supported binary variables discussed previously, the underlying unrestricted model saw the trace correlation, a goodness-of-fit indicator, nearly double to 0.626 ; evidence suggested that serial correlation and heteroscedasticity were not issues; and indicators of skewness and kurtosis improved and ultimately fell within accepted levels. From this information, we conclude that we met literature-established evidential standards that permit us to conclude that we achieved a statistically adequate underlying unrestricted model for which cointegration properties may be tested and exploited. The diagnostic results exhibited in Table 1 not only render us confident that inclusion of the various binary variables noted previously was accomplished in a properly implemented procedure as described in Juselius (2006) but also that we avoided wellknown econometric consequences that potentially arise from excessive use and/or misspecification of such binary variables.

\subsection{Testing for cointegration, imposing appropriate rank of $\Pi$, and testing for time invariance of parameter estimates}

Equation (2) shows that $\Pi$ is a $p \times p$ (here 4 by 4) matrix equal to the product of two $p$ by $r$ matrices, where $r$ is the reduced rank of $\Pi$ and represents the number of cointegrating relations or CVs that error correct the system of our four individually nonstationary prices. Testing for the appropriate $r$ is a test for cointegration. Under cointegration, the rank of $\beta^{\prime} \times x(t-1)$ is reduced from $p=4$ (i.e., $r<p$ ), and $r$ may range from 1 to 3 . The literature has widely employed Johansen and Juselius's (1990) nested trace tests to ascertain $\Pi$ 's reduced rank or $r$. Table 2 provides nested trace test statistics and test results. Evidence at the 5\% significance level was sufficient to reject the first null hypothesis that $r \leq 0$ and was insufficient to reject the second (that $r \leq 1$ ), as well as the third and fourth, null hypotheses. These nested results suggest that $\Pi$ 's reduced rank is $r=1$ and that a single $\mathrm{CV}$ corrects the system. A reduced rank of $r=1$ was then imposed on $\Pi$.

Table 2. Nested trace test statistics and test results

\begin{tabular}{cccc}
\hline Null Hypothesis & Trace Value & Critical Value & Test Result \\
\hline Rank or $r \leq 0$ & 86.57 & 63.66 & Reject the null that $r \leq 0$ \\
\hline Rank or $r \leq 1$ & 38.23 & 42.77 & Fail to reject the null that $r \leq 1$ \\
\hline Rank or $r \leq 2$ & 17.23 & 25.73 & Fail to reject the null that $r \leq 2$ \\
\hline Rank or $r \leq 3$ & 4.85 & 12.45 & Fail to reject the null that $r \leq 3$ \\
\hline
\end{tabular}


As instructed by Juselius (2006, chap. 9), one should test for the time invariance (or constancy) of estimated parameters, and she offers the "known-beta" test programmed in Estima (2012) to do so. The known-beta procedure (see Juselius 2006, chap. 9) formally tests the null hypothesis that parameter estimates of the cointegrated model (with the imposed restriction of $\Pi$ having the rank of here $r=1$ ), including GEEVENT defined for the 2013 U.S. wheat contamination, are constant or time invariant over the entire sample including the sample's June-December 2013 subperiod after the time of the contamination's occurrence. Following Juselius (2006, chap. 9) and Babula et al.'s (2006, p. 47) application of the test to a cointegrated VAR analysis of monthly prices of U.S. sugar-related products, test values (normalized by a $5 \%$ critical value and asymptotically distributed as a chi-squared distribution) were all less than unity. This finding in turn suggests that the parameter estimates of our model (including the GEEVENT estimate) are time invariant and, hence, are valid over the entire sample period. Evidence and analysis in the preceding paragraph and in Section 5.4 suggests that although the contamination event modeled by GEEVENT did have an effect, the contamination event did not elicit time variance of coefficients (did not elicit a structural break), and the estimates imputed from GEEVENT are valid. In other words, formal statistical evidence suggests that for the 2013 wheat contamination event, a structural break or parameter time variance was not an issue.

This statistical evidence that the 2013 wheat contamination of focus did not elicit a structural break is the principal difference between this study and the Carter and Smith (2007) and Li et al. (2010) inquiries on the U.S. price effects of the U.S. corn and rice contaminations, respectively. Ours is the only one of the three studies where formal statistical analysis (known-beta test results) suggested that there was not a structural break. So given the time invariance and valid interpretation of the shifter or the binary GEEVENT's coefficient over the whole sample, one is not compelled to split the full sample, as did Carter and Smith (2007) and Li et al. (2010), into pre- and postcontamination subsamples so as to ultimately estimate contamination-induced price effects.

The time-invariant GEEVENT coefficient is valid over the full sample (before and after the 2013 contamination event), and being defined for the contamination event per se, the GEEVENT coefficient estimate may be used as discussed in Section 5.4 to discern empirically the contamination-induced price effects (Juselius 2006; Patterson 2000, p. 195). In our study's case without a contamination-induced structural break, and under the important caveat that our four modeled U.S. wheat price variables provide a statistically adequate reduced-form cointegration model as our specification discussion in Section 5.2 shows that we have done, one should not split the sample into pre- and postcontamination subsamples. In addition, the importance of finding a nonwheat or non-U.S. wheat substitute price as a noncontaminated "control" as Carter and Smith (2007) found for corn in sorghum price is not as crucial or necessary. Given a statistically adequate cointegrated VAR model of the four substitute wheat prices, and given our finding (Table 2) of one cointegrated relationship normalized on spring red hard wheat price, then the GEEVENT estimate likely ferrets out the contamination-induced effects on U.S. spring red hard wheat price without needing to throw in a control variable from an outside market. Finally, Carter and Smith's (2007) recommended modeling strategy of using a cointegrated VAR or VEC model with a shifter must have been for cases such as ours without structural breaks over the entire sample; otherwise the recommended shifter's coefficient estimate would not have been constant (i.e., would have been time variant) and not valid for discerning contamination-induced effects.

\subsection{An estimate of GE event-induced price declines on spring red hard wheat}

Following Johansen and Juselius (1990) and Juselius (2006), we normalized the cointegrating relationship on the price of spring red hard wheat (PSPRRDHD) and subsequently conducted a series of hypothesis tests concerning model specification. We imposed the restrictions that were 
Table 3. Estimates of national damages to U.S. spring red hard wheat farmers

\begin{tabular}{|c|c|c|c|c|c|}
\hline A & B & C & D & $E$ & $\mathrm{~F}$ \\
\hline $\begin{array}{l}\text { Projected } \\
\text { Price } \\
\text { (\$/bushel) }\end{array}$ & $\begin{array}{l}\text { Projected Production } \\
\text { June 2013-May } 2014 \\
\text { (million bushels) }\end{array}$ & $\begin{array}{l}\% \text { Projected } \\
\text { Production Sold on } \\
\text { Spot Market }\end{array}$ & $\begin{array}{l}\text { Projected Lost Receipts } \\
\text { for U.S. Wheat Farmers } \\
\text { (million \$) }\end{array}$ & $\begin{array}{l}\% \text { Drop in } \\
\text { PSPRRDHD }\end{array}$ & $\begin{array}{l}\text { Drop in } \\
\text { PSPRRDHD } \\
\text { (\$/bushel) }\end{array}$ \\
\hline \multirow[t]{4}{*}{6.97} & 490.39 & 100 & -131.04 & -3.83 & -0.27 \\
\hline & & 75 & -98.28 & & \\
\hline & & 50 & -65.53 & & \\
\hline & & 25 & -32.76 & & \\
\hline
\end{tabular}

Notes: Columns A and B are based on U.S. Department of Agriculture projections that were available during the noted litigation in late 2013 (U.S. Department of Agriculture, Economic Research Service, 2013). Column C is based on assumptions made by the authors. Column D is based on calculations using columns $\mathrm{A}, \mathrm{B}$, and $\mathrm{C}$ and the price reduction estimate. The estimated coefficient on the GEEVENT binary is -0.03909159 . When the base of the natural logarithm is raised to the power of this coefficient estimate, and 1.0 is subtracted from it, and this result is multiplied by 100 , one obtains the econometric price reduction estimate of $-3.8337374 \%$ or -0.0383 reported in the table. So consider the $-\$ 98.28$ million loss of receipts in column D under the assumption that $75 \%$ of the U.S. spring red hard wheat was marketed on the spot market. This estimate of lost receipts is calculated as the $\$ 6.97$ price times -0.038337374 times 490.39 million bushels times 0.75 . Column $\mathrm{F}$ is calculated as $\$ 6.97$ times -0.038337374 . PSPRRDHD, price of spring red hard wheat.

accepted by the hypothesis tests and then reestimated the single CV normalized on PSPRRDHD. ${ }^{5}$ The coefficient on the GEEVENT binary variable was the part of the CV of direct relevance to our previously discussed analytical purpose.

When the CV is normalized on PSPRRDHD, and because the estimations were done in doublelog format, then one may invoke Halvorsen and Palmquist's (1980) well-known convention of interpreting the GEEVENT coefficient estimate of -0.03909159 . Following this convention, an estimate arises of $-3.83 \%$ for the GE event-induced reduction in the price of spring red hard wheat. More specifically, we raised $e$, the base of the natural logarithm, to the power of the econometric GE-event binary coefficient estimate $(-0.03909159)$ and subtracted 1 to get -0.03833787 . The coefficient suggests that on average, the price of spring red hard wheat was about $3.83 \%$ lower during the 2 months following occurrence of the May 2013 GE event (the GEEVENT binary's period of definition) than during other parts of the sample period. This reduction in price is consistent with findings of a contamination-elicited price decline for the commodities of focus in Carter and Smith (2007) for corn and in Li et al. (2010) for rice.

\subsection{Estimated national effects on price and receipts from the May 2013 GE event}

Table 3 provides a method to calculate the national effects attributed to the May $2013 \mathrm{GE}$ event on price and receipts of U.S. spring red hard wheat farmers. These effects demonstrate the calculation procedures employed in late 2013/early 2014 when actual court cases were filed in response to the noted event. As such, the procedures use the most reasonable assumptions and the most accurate

\footnotetext{
${ }^{5}$ The entire cointegrating relationship is as follows:

PSPRRDHD $=(1.198 \times$ PWINRDHD $)+(1.1804 \times$ PWINRDSF $)-(1.096 \times$ PWINWHSF $)-(0.0391 \times$ GEEVENT $)-$ $(0.202 \times \mathrm{FB} 2008)+(0.152 \times$ RECESS $)$. In this relation, and following earlier work on monthly U.S. wheat prices (Babula, 2011, pp. 112-23), the trend is restricted to zero. Two of the four prices generated positive coefficients, and we conjecture that these opposing price patterns may have arisen from trade-offs in wheat usage and producers for whom certain classes of wheat are competing for acreage. The GEEVENT coefficient of -0.0391 was actually generated as -0.03909159 with the latter used for damage calculations. Focused on methodology here, we realize that some may think that the model estimated should have included other variables. We relegate this issue to future research and note that in spite of what some may consider an overly simple all-price endogenous variable setting, our efforts are nonetheless valid for two reasons. First, we meet, for our chosen model of U.S. non-durum wheat prices, accepted statistical and diagnostic standards clearly reflected in Table 1. Second, our "inclusion of co-integrating relationships enhances structure in that they remain invariant to expansions in the information set" (Bardsen, Fischer, and Nymoen, 1994, p. 506). So future research could expand our modeled information set while our results here remain valid.
} 
projections of price reductions, spring red hard wheat production, and crop percentages sold on the spot market as were available by economists and attorneys who participated in the noted class action cases.

Column A provides the projected price of spring red hard wheat, PSPRRDHD, the average of the USDA's monthly PSPRRDHD values for the June-December 2013 period immediately following the May 2013 GE event (USDA-NASS, 2018). ${ }^{6}$ Column B provides the USDA's projected June 2013-May 2014 spring red hard wheat production (490.39 million bushels) as reported in the Wheat Outlook report that had most recently been published in the immediate aftermath of the May 2013 event and available to litigators in late 2013 (see USDA-ERS, 2013). The impact estimates on national spring red hard wheat receipts are therefore conditional estimates and hinge on assumed proportions of the postevent June 2013/May 2014 market year crop that would have been sold on the spot market immediately after the event. Generally unknown, we provide four alternative assumptions for these proportions in column C.

Column D provides projected declines in U.S. receipts for spring red hard wheat attributed to the May 2013 GE event. The econometrically estimated event-induced decline in PSPRRDHD, $-3.83 \%$ is in column E. As a result, column D provides the projected damages, in terms of decreased receipts to U.S. spring red hard wheat under four alternative assumptions of percentages of the crop sold onto the spot market in late 2013/early $2014 .^{7}$ Column $\mathrm{F}$ is the estimated 3.83\% GE event-induced price reduction estimate applied to $\$ 6.97$ projected price in dollars per bushel.

In summary, using our methodology as exhibited in Table 3 would generate estimated damages from the May 2013 GE event to U.S. spring red hard wheat farmers of lost receipts that ranged from \$32.76 million to \$131.04 million from a GE event-induced drop in PSPRRDHD of $3.83 \%$ or $\$ 0.27$ per bushel. Because of space considerations, and given our goal of methodology development, we provide such estimates in Table 3 only for spring red hard wheat and remind readers that analogous tables may be calculated for the other three noted U.S. wheat classes.

\subsection{Estimated effects on a hypothetical plaintiff farmer's price and receipts from the May 2013 GE event}

Table 4 provides how the econometrically estimated drop in price, $-3.83 \%$, may be used to estimate plaintiff-farm-specific declines in spring red hard wheat price and in receipts from the May 2013 GE event. Given the confidentiality of farm-specific financial records that may not be published herein, the data exhibited in Table 4 are based on records of a hypothetical plaintiff farmer's wheat transactions during June 2013, soon after the event. In conferring with extension economists who possess actual records, these hypothetical records were deemed reasonable. The methodology suggests that occurrence of the May 2013 GE event resulted in a reduction of $\$ 0.31$ per bushel price received from $\$ 8.04$ to $\$ 7.73$. The actual price received of $\$ 7.73$ per bushel (column 3 ) is adjusted into a higher (hypothetical) price that would have occurred had the GE event of May 2013 not taken place-\$8.04 per bushel (column 4). This latter hypothetical price of $\$ 8.04$ per bushel was obtained by dividing $\$ 7.73$ by the econometrically estimated price

\footnotetext{
${ }^{6}$ This average price of $\$ 6.97$ is the mean of the following June-December 2013 PSPRRDHD values, published by USDANASS (2018): $\$ 7.73, \$ 7.29, \$ 6.98, \$ 6.72, \$ 6.85, \$ 6.70$, and $\$ 6.53$, respectively.

${ }^{7}$ For example, the high level of estimated lost receipts is $\$ 131.04$ million under the extreme assumption that $100 \%$ of production was sold on the spot market. This level is calculated as the projected price of $\$ 6.97$ (column A) times projected 2013/2014 market year production of 490.39 million bushels (column B) times ( -0.038337374 ), the estimated GE eventinduced reduction in PSPRRDHD. As previously noted, the latter estimate is obtained by raising $e$, the base of the natural logarithm, to the power of $(-0.03909159)$, the econometric coefficient estimate generated by the GEEVENT binary variable and subtracting 1.0 .
} 
Table 4. Estimation of hypothetical damages to a spring red hard wheat farmer

\begin{tabular}{lcccccc}
\hline Date & $\begin{array}{c}\text { Volume Sold } \\
\text { (bushels) }\end{array}$ & $\begin{array}{c}\text { Actual Price } \\
\text { Received }(\$)\end{array}$ & $\begin{array}{c}\text { Projected Price } \\
\text { Received (\$) }\end{array}$ & $\begin{array}{c}\text { Actual } \\
\text { Receipts (\$) }\end{array}$ & $\begin{array}{c}\text { Projected } \\
\text { Receipts (\$) }\end{array}$ & $\begin{array}{c}\text { Lost } \\
\text { Receipts (\$) }\end{array}$ \\
\hline $\begin{array}{l}\text { June } 10, \\
2013\end{array}$ & 15,600 & 7.73 & 8.04 & 120,588 & 125,395 & 4,807 \\
\hline
\end{tabular}

decline factor of 0.961662626 that in turn is the base of the natural logarithm, $e$, raised to the power of the previously noted GEEVENT coefficient estimate $(-0.03909159) .{ }^{8}$

Further, this article provides a contribution by taking a national price effect estimate from modeling strategies similar to Carter and Smith's (2007) and Li et al.'s (2010) general modeling strategies and then translating them, for the first time in the literature, to farm-specific plaintiffs for use in litigation. Actual and projected receipts are the volume sold multiplied by the actual and projected prices received in columns 5 and 6 (Table 4), respectively. In turn, the negative difference in the actual and projected receipts represents the damages in terms of lost farm receipts attributed to the May 2013 GE event in column 7 (Table 4). In this hypothetical plaintiff s case, our methodology estimates that $\$ 4,807$ in lost receipts was attributed to the May $2013 \mathrm{GE}$ event.

As insightfully noted by an anonymous reviewer, there are other factors not accounted for that could increase or decrease the adverse economic effects of the 2013 GE/RR contamination of U.S. wheat supplies. These other factors include various transaction costs associated with "cleaning" the wheat in the U.S. supply chain, costs of testing for the presence of a GM contaminant, and restructuring of export shipments from countries that imposed the ban and those countries that did not.

\section{Summary and conclusions}

In May 2013, the U.S. government announced that a GE strain of wheat contaminated non-GE supplies of U.S. wheat. As a result, and within 2 months of the event, an array of consequences emerged that included, among other things, cancellation of a number of foreign nations' purchase order contracts of U.S. wheat and declines in wheat prices and wheat futures prices. It was widely reported that such alleged consequences associated with the May 2013 GE event would likely result in declines in U.S. wheat prices and U.S. wheat receipts (Bjerga, 2013; Boone, 2013; Jalonick, 2013; Klein, 2013; Thukral and Maeda, 2013). Class action by certain wheat farmers against the developer of the contaminating GE wheat strand soon occurred in late 2013/early 2014.

Previous studies utilized time-series cointegration modeling methodologies to assess U.S. crop sector-level price declines induced by crop contamination events (Carter and Smith, 2007; Li et al., 2010). Yet to date, no studies have been located that extend the sector-level adverse price effect estimates to the farm-specific plaintiffs for use in litigation that often follows such contamination events and that occurred after the $2013 \mathrm{GE} / \mathrm{RR}$ wheat contamination incident. Consequently, we develop a methodology with which to accurately empirically assess the damaging impacts of the May 2013 GE event on U.S. wheat farmers nationally and at the plaintiff farm level. Implicit in this specific case was the need to establish a methodology by which damages from such a crop supply contamination event may be assessed for producers generally at the national level and at the producer/plaintiff level.

This methodology combines econometric modeling and simple accounting procedures in order to empirically assess national and plaintiff farm-specific damages in the form of declines in wheat

\footnotetext{
${ }^{8}$ The GEEVENT binary's beta estimate is -0.03909159 . The price decline factor is $[e(-0.03909159)]=0.961662626$. The actual per bushel price of $\$ 7.73$ is divided by the factor of 0.961662626 to render a per bushel projected price of $\$ 8.04$ that would have occurred had the May 2013 GE event not occurred.
} 
price and wheat receipts that were estimated to have emerged from contamination of the U.S. wheat supply in May 2013. Throughout, we illustratively applied the methodology to the national market for and to a hypothetical individual plaintiff farmer of the U.S. spring red hard wheat class and within the time frames required of the class action litigation that occurred after the actual May 2013 GE event. We offer this summary of the methodology as a more general way for the economics profession to similarly assess damages for contamination of other U.S. wheat class markets and, more generally, for other commodity or food market supplies that may become contaminated.

The methodology entails four steps: (1) to determine the product market affected; (2) to develop a method to model appropriate markets in order to empirically assess the monitored event-induced effect on the national product price; (3) to apply the estimated event-induced U.S. price decline to production projections at the time of litigation (these projections should be the most recent available at the time of the litigation and are applied to provide estimates of declines in U.S. receipts of the monitored market); and (4) to apply the event-induced price effect to plaintiff-specific sales records, prices received, and receipts to estimate event-induced damages in terms of prices received and lost sales receipts.

The methodology was applied to the U.S. spring red hard wheat industry in the wake of the May 2013 GE event. Results suggest that U.S. spring red hard wheat farmers lost receipts that ranged from $\$ 32.77$ million to $\$ 131.06$ million and incurred a drop in spring red hard wheat prices of $3.83 \%$ or $\$ 0.27$ per bushel. At the farm level, our methodology suggests that a hypothetical farmer received $\$ 0.31$ less per bushel because of the May $2013 \mathrm{GE}$ event in this event's immediate 2013 aftermath. In this plaintiffs case, our methodology estimates that $\$ 4,807$ in lost receipts was attributed to the May 2013 GE event.

Acknowledgments. The authors are indebted to the editor and three anonymous reviewers for their insightful comments that improved the manuscript.

\section{References}

Babula, R.A. "Using Cointegrated VAR Modeling to Comparatively and Empirically Assess Effects of Alternatively-Focused on U.S. Soft Wheat Markets.” Journal of International Agricultural Trade and Development 7,2(2011):109-30.

Babula, R.A., D. Newman, and R.A. Rogowsky. "A Dynamic Model of U.S. Sugar-Related Markets: A Cointegrated Vector Autoregression Approach.” Journal of Food Distribution Research 37,2(2006):35-59.

Bardsen, G., P. Fischer, and R. Nymoen. "Business Cycles: Real Facts or Fallacies?” Working Papers, Bergen: Norwegian School of Economics and Business Administration, 1994. Internet site: http://EconPapers.repec.org/RePEc:fth:norgee: 20-94 (Accessed April 15, 2019).

Bjerga, A. "Monsanto Modified Wheat Not Approved by USDA in Field.” Bloomberg, May 30, 2013. Internet site: https:// www.bloomberg.com/news/articles/2013-05-29/monsanto-modified-wheat-unapproved-by-usda-found-in-oregon-field (Accessed May 20, 2018).

Boone, R. "Idaho Farmers Sue Monsanto over GMO Wheat." Morning Call, 2013. Internet site: https://www.mcall.com/sdutidaho-farmers-sue-monsanto-over-gmo-wheat-2013jun12-story.html (Accessed May 18, 2019).

Carter, C.A., and A. Smith. "Estimating the Market Effect of a Food Scare: The Case of Genetically Modified StarLink Corn." Review of Economics and Statistics 89,3(2007):522-33.

Clements, S, A. Tidwell, and C. Jin. "Futures Markets and Real Estate Public Equity: Connectivity of Lumber Futures and Lumber REITS." Journal of Forest Economics 28(August 2017):70-79.

Dennis, J. CATS in RATS: Co-integration Analysis of Time Series, Version 2. Evanston, IL: Estima, 2006.

Dickey, D.A., and W.A. Fuller. "Likelihood Ratio Statistics for Autoregressive Time Series with a Unit Root." Econometrica 49,4(1981):1057-72.

Engle, R.F., and C.W.J. Granger. "Co-integration and Error Correction: Representation, Estimation, and Testing." Econometrica 55,2(1987):251-76.

Engle, R.F., and B.S. Yoo. "Forecasting and Testing in Co-integrated Systems." Journal of Econometrics 35,1(1987):143-59.

Estima. RATS: Regression Analysis of Time Series, Version 8.2. Evanston, IL: Estima, 2012.

Haavelmo, T. "The Probability Approach in Econometrics." Econometrica 12, Supplement (July 1944):1-115.

Halvorsen, R., and R. Palmquist. "The Interpretation of Dummy Variables in Semi-logarithmic Equations." American Economic Review 70,3(1980):474-75. 
Hamilton, J.D. Time Series Analysis. Princeton, NJ: Princeton University Press, 1994.

Jalonick, M.C. "USDA: Non-Approved Generically Modified Wheat Found in Oregon Field." Associated Press, 2013. Internet site: https://kcby.com/news/local/usda-non-approved-genetically-modified-wheat-found-in-oregon-field-11-13-2015-173206166 (Accessed May 18, 2019).

Johansen, S., and K. Juselius. "Maximum Likelihood Estimation and Inference on Cointegration-with Applications to the Demand for Money." Oxford Bulletin of Economics and Statistics 52,2(1990):169-210.

Juselius, K. The Co-integrated VAR Model: Methodology and Applications. Oxford: Oxford University Press, 2006.

Juselius, K., and M. Franchi. "Taking a DSGE Model to the Data Meaningfully." Economics: The Open-Access, OpenAssessment E-Journal 4(2007):1-38.

Juselius, K., and J. Toro. "Monetary Transmission Mechanisms in Spain: The Effect of Monetization, Financial Deregulation, and the EMS." Journal of International Money and Finance 24,3(2005):509-31.

Klein, P. "Monsanto's Genetically Engineered Wheat Scandal Is No Surprise." Forbes. 2013. Internet site: https://www.forbes. $\mathrm{com} /$ sites/forbesleadershipforum/2013/06/05/monsantos-genetically-engineered-wheat-scandal-is-no-surprise/\#4356f8281ea8 (Accessed May 18, 2019).

Li, Y., E.J. Wailes, A. McKenzie, and M. Thomsen. "LL601 Contamination and Its Impact on U.S. Rice Prices." Journal of Agricultural and Applied Economics 42,1(2010):31-38.

Patterson, K. An Introduction to Applied Econometrics: A Time Series Approach. New York: Palgrave, 2000.

Rubinfeld, D.L. "Econometrics in the Courtroom." Columbia Law Review 85,5(1985):1048-97.

Sims, C.A. "Models and Their Uses." American Journal of Agricultural Economics 71,2(1989):489-94.

Thukral, N., and R. Maeda. "Japan Cancels GMO Wheat Order after Concerns over U.S. Grain Developed by Monsanto." Huffington Post, 2013. Internet site: https://www.huffpost.com/entry/japan-gmo-wheat-food-concerns_n_3357240 (Accessed May 18, 2019).

U.S. Department of Agriculture, Animal and Plant Health Inspection Service (USDA-APHIS). "Glyphosate-Resistant Wheat Incidents.” 2018. Internet site: https://www.aphis.usda.gov/aphis/ourfocus/biotechnology/hot_topics/glyphosate_ resistant_wheat/wheat_investigation (Accessed May 18, 2019).

U.S. Department of Agriculture, Economic Research Service (USDA-ERS). "Wheat Outlook No. WHS-132, Table 2, Wheat by Class, US Market Year Supply and Disappearance, December 12 2013.” 2013. Internet site: https://www.ers.usda.gov/ publications/pub-details/?pubid=39928 (Accessed May 19, 2018, and March 6, 2019).

U.S. Department of Agriculture, National Agricultural Statistics Service (USDA-NASS). "Monthly Per-Bushel US Wheat Prices by Class." 2018. Internet site: https:/quickstats.nass.usda.gov/results/CC7B67D9-785C-3A47-ABED-FF92BD505775 (Accessed May 21, 2018).

Cite this article: Capps O, Jr. and Babula RA (2019). A Methodology to Empirically Assess National and Farm-Specific Damages from Contamination of Grain Supply by a Genetically Engineered Strain. Journal of Agricultural and Applied Economics 51, 495-510. https://doi.org/10.1017/aae.2019.16 